\title{
Morphology, Molecular Phylogeny and Pathogenicity of Colletotrichum panacicola Causing Anthracnose of Korean Ginseng
}

\author{
Kyung Jin Choi ${ }^{1}$, Wan Gyu Kim ${ }^{1}$, Hong Gi Kim² ${ }^{2}$ Hyo Won Choi', Young Kee Lee', Byung Dae Lee ${ }^{3}$, \\ Sang Yeob Lee ${ }^{4}$ and Sung Kee Hong ${ }^{1 *}$ \\ ${ }^{1}$ Crop Protection Division, National Academy of Agricultural Science (NAAS), RDA, Suwon 441-707, Korea \\ ${ }^{2}$ Department of Agricultural Biology, Chungnam National University, Daejeon 305-704, Korea \\ ${ }^{3}$ Bioresource Development Institute, Herbking Inc. Hankyong University, Anseong 456-749, Korea \\ ${ }^{4}$ Agricultural Microbiology Team, NAAS, RDA, Suwon 441-707, Korea \\ (Received on December 6, 2010; Accepted on February 7, 2011)
}

Colletotrichum panacicola isolates were obtained from anthracnose lesions of Korean ginseng and compared with four Colletotrichum species in morphology, molecular phylogeny and pathogenicity. Based on morphological characteristics, $C$. panacicola was easily distinguished from Colletotrichum gloeosporioides but not from Colletotrichum higginsianum, Colletotrichum destructivum and Colletotrichum coccodes. A phylogenetic tree generated from ribosomal DNA-internal transcribed spacer sequences revealed that $C$. panacicola is remarkably distinguished from $C$. gloeosporioides and $C$. coccodes but not from $C$. higginsianum and $C$. destructivum. However, molecular sequence analysis of three combined genes (actin + elongation factor- $1 \alpha+$ glutamine synthatase) provided sufficient variability to distinguish C. panacicola from other Colletotrichum species. Pathogencity tests showed that $C$. panacicola is pathogenic to Korean ginseng but not to other plants. These results suggest that $C$. panacicola is an independent taxon distin-zguishable from $C$. gloeosporioides and other morphologically similar Colletotrichum species.

Keywords : Anthracnose, Colletotrichum gloeosporioides, Colletotrichum panacicola, Korean ginseng

Korean ginseng (Panax ginseng Mey) is one of the most important medicinal crops being cultivated in Korea. The area of cultivation has been increased throughout the country due to high demand. Several diseases occur in ginseng during 5 to 6 years of cultivation. Most ginseng diseases are caused by fungi. Of these, anthracnose causing seedling blight in nurseries and leaf spot in permanent beds is one of the most destructive diseases (Chung and Bae, 1979).

\footnotetext{
*Corresponding author.

Phone) +82-31-290-0415, FAX) +82-31-290-0453

E-mail)sukihong@korea.kr
}

In Korea, Colletotrichum panacicola recorded as a causal pathogen of Korean ginseng anthracnose (Takimoto, 1919) has been considered to be a synonym of Colletotrichum gloeosporioides without any basis that these two species are the same taxon. Accordingly, there is a need for a comprehensive approach for confirming the taxonomical position of $C$. panacicola. This study was conducted to compare morphology, molecular phylogeny and pathogenicity of C. panacicola, C. gloeosporioides and morphologically similar Colletotrichum species.

\section{Materials and Methods}

Isolation of pathogenic fungi. Colletotrichum isolates were obtained from leaves or fruits of Korean ginseng, Chinese cabbage, radish, soybean, potato, tomato and chili pepper with symptoms of anthracnose. The symptomatic tissues were surface-sterilized by immersion in $1 \% \mathrm{NaOCl}$ for 1 minute followed by two rinses in sterile distilled water. The blotted tissues were transferred to water agar (WA) plates and incubated at $25^{\circ} \mathrm{C}$ for 3 days. Conidia produced on the tissues were suspended with sterile distilled water, streaked on WA plates and incubated at $25^{\circ} \mathrm{C}$ for 18 to 24 hours. Monoconidial isolates were obtained from germinating spores on WA and transferred to potato dextrose agar (PDA) slants.

Morphological and cultural characteristics. The Colletotrichum isolates were cultured on PDA plates in darkness at $23{ }^{\circ} \mathrm{C}$ for 7 days. The culture plates were transferred into an incubator with alternating cycles of $12 \mathrm{~h}$ NUV light and 12 $\mathrm{h}$ darkness for another week to induce conidial production. The conidia harvested from each isolate were mounted in water and their morphological features were examined using a light microscope. To observe appressorial formation, a drop of conidial suspension $\left(5 \times 10^{5}\right.$ conidia $\left.\cdot \mathrm{mL}^{-1}\right)$ was dropped on sterilized slide glass in petri-plates with water- 
soaked filter paper and kept at $25^{\circ} \mathrm{C}$ for 16 to 24 hours. Mycelial growth and colony features of the isolates were examined on PDA plates kept in darkness at $26^{\circ} \mathrm{C}$ for a week. The colony colors were described using the Munsell renovation color system (Nippon Shikisai Co. Ltd.).

Extraction of genomic DNA, amplification and phylogenetic analysis. Colletotrichum isolates were cultured in potato dextrose broth at $25^{\circ} \mathrm{C}$ for 4 days. The mycelial mats were lyophilized for 16 hours and homogenized at 5,800 rpm for 40 seconds using the Precellys ${ }^{\circledR} 24$ (Bertin technologies). Genomic DNA was extracted with a modified CTAB method (Stewart and Via, 1993). The internal transcribed spacer (ITS) region of rDNA was amplified with primers ITS1 and ITS4 (White et al., 1990). Actin, elongation factor-1 alpha (EF-1 $\alpha$ ), and glutamine synthatase (GS) genes were amplified with primer sets ACT-512F/ACT783R (Carbone and Kohn, 1999), EF1-526F/EF1-1567R (Rehner, 2001), and GSF1/GSR1 (Guerber et al., 2003), respectively. The PCR reactions were performed in a total volume of $50 \mu \mathrm{l}$ including 100ng genomic DNA, $5 \mu \mathrm{l}$ of $10 \times$ PCR buffer containing $25 \mathrm{mM} \mathrm{MgCl}_{2}, 0.2 \mathrm{mM} \mathrm{dNTP}$, $0.2 \mu \mathrm{M}$ of each primer and 1 unit of Taq DNA polymerase (Takara Bio Inc.) using a DNA Engine Tetrad $^{\circledR} 2$ (Bio-Rad laboratories Inc.). Thermal conditions were programmed for 35 cycles of denaturation $\left(94^{\circ} \mathrm{C}\right.$ for $\left.50 \mathrm{sec}\right)$, annealing $\left(60^{\circ} \mathrm{C}\right.$ for $\left.1 \mathrm{~min}\right)$ and extension $\left(72^{\circ} \mathrm{C}\right.$ for $\left.1 \mathrm{~min} 20 \mathrm{sec}\right)$. PCR products were purified with Wizard ${ }^{\circledR} \mathrm{SV}$ gel and PCR clean-up system (Promega) following manufacturer's instructions. The eluted DNAs were cloned into pGEM-T easy vector (Promega) and transformed into Escherichia coli JM109. True transformants were selected and sequenced with 3730XL DNA Analyzer (Applied Biosystems). Two phylogenies were generated from the ITS region sequences and from the combined data of actin, EF1- $\alpha$ and GS genes. Sequence alignments were performed using Clustal $\mathrm{X}$ ver.
2.0.10 (Thompson et al., 1997). Nucleotide sequences of Colletotrichum isolates were deposited in GenBank (http:// www.ncbi.nlm.nih.gov) and are listed in Table 1. Phylogenetic trees were constructed by neighbor-joining method (Saitou and Nei, 1987) with pairwise deletion parameters of Kimura's two-parameter model (Kimura, 1980) using MEGA version 4.0 (Tamura et al., 2007). Confidence of phylogenetic trees was supported with bootstrap method for 1,000 replicates (Felsenstein, 1985).

Pathogenicity assay. Tri-folia leaves of 4-year old ginseng, leaves of 3-week old tomato cultivar 'seokwang', leaves of 3-week old soybean cultivar 'daepoong' and leaves of 3week old radish cultivar 'taegeun' were used for pathogenicity assays. Leaves were wounded with blunt pencil tips or left unwounded. Fifteen $\mu$ of conidia suspension $\left(5 \times 10^{5}\right.$ conidia $\cdot \mathrm{ml}^{-1}$ ) was used to inoculate wounded and unwounded sites of the leaves. The inoculated leaves were placed in plastic containers $(230 \times 295 \times 55 \mathrm{~mm})$ layered with moist paper towels, and kept at $26^{\circ} \mathrm{C}\left( \pm 1{ }^{\circ} \mathrm{C}\right)$. Disease severity on ginseng, radish and tomato was based on lesion diameter measured 5 days after inoculation and disease severity on soybean was based on lesion diameter measured 10 days after inoculation on soybean.

\section{Results}

Morphological and cultural characteristics. Three $C$. panacicola isolates from leaves and fruits of Korean ginseng, two Colletotrichum higginsianum isolates from Chinese cabbage and radish, Colletotrichum destructivum isolate from soybean, two Colletotrichum coccodes isolates from potato and tomato, and two C. gloeosporioides isolates from chili pepper were used to compare their morphological and cultural characteristics (Table 1). Remarkable differences in conidial morphology between $C$. panacicola

Table 1. Colletotrichum species studied genetically and/or morphologically

\begin{tabular}{lcccccc}
\hline \hline \multirow{2}{*}{$\begin{array}{l}\text { Species } \\
\text { Isolate }\end{array}$} & Source of isolate & \multicolumn{4}{c}{ Accession no. } \\
\cline { 4 - 7 } & & ITS & Actin & EF-1 $\alpha$ & GS \\
\hline C. panacicola & C08048 & Korean ginseng & GU935867 & GU944757 & GU935827 & GU935807 \\
& C08061 & Korean ginseng & GU935868 & GU935791 & GU935828 & GU935808 \\
& C08087 & Korean ginseng & GU935869 & GU944758 & GU935829 & GU935809 \\
C. higginsianum & C97027 & Chinese cabbage & GU935870 & GU935792 & GU935830 & GU935810 \\
& C08122 & Radish & GU935873 & GU935794 & GU935833 & GU935813 \\
C. destructivum & C08077 & Soy bean & GU935874 & GU935795 & GU935834 & GU935814 \\
C. coccodes & C07046 & Potato & GU935877 & GU935798 & GU935837 & GU935817 \\
& C96002 & Tomato & GU935875 & GU935796 & GU935835 & GU935815 \\
C. gloeosporioides & C07008 & Chili pepper & GU935879 & GU935800 & GU935839 & GU935819 \\
& C07009 & Chili pepper & GU935880 & GU935801 & GU935840 & GU935820 \\
\hline
\end{tabular}




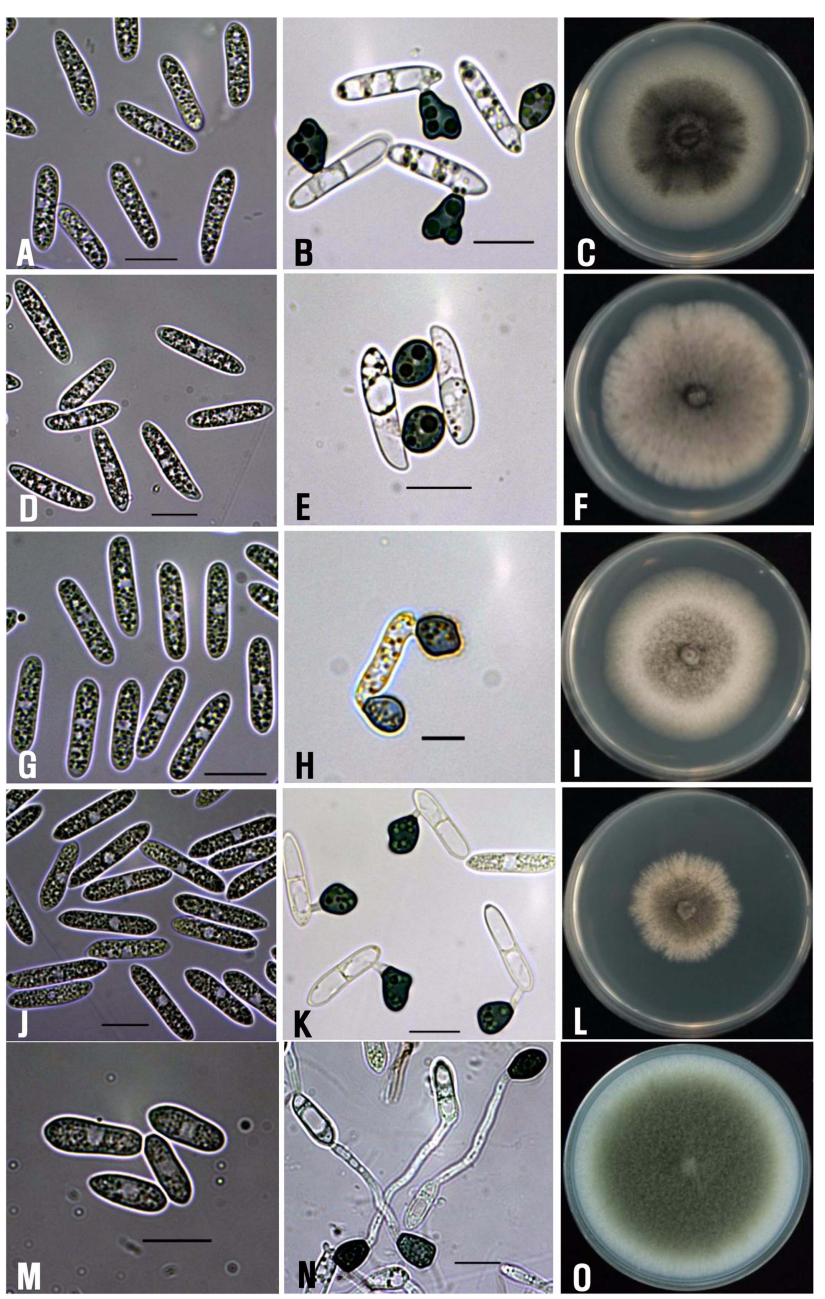

Fig. 1. Conidia, appressoria and colonies of Colletotrichum spp. A to $\mathrm{C}, C$. panacicola; D to F, $C$. higginsianum; $\mathrm{G}$ to I, $C$. destructivum; J to L, C. coccodes; $\mathrm{M}$ to $\mathrm{O}, C$. gloeosporioides. Three vertical rows from left to right denote conidia, appressoria and colonies, respectively. All scale bars represent $10 \mu \mathrm{m}$.

and C. gloeosporioides were observed (Fig. 1; Table 2). C. panacicola isolates were straight or slightly unilaterally curved, with a round apex and a subconical base, measuring $11.2-20.5 \times 3.3-4.8 \mu \mathrm{m}$, with a mean range of $16.4-18.3 \times$ 4.0-4.4 $\mu \mathrm{m}$, matching well with previous descriptions of the fungi (Nakata and Takimoto, 1922). C. gloeosporioides isolates were usually straight, broad cylindrical with rounded both ends or pointed to one end, measuring 10.0 $22.9 \times 3.8-6.5 \mu \mathrm{m}$, with a mean range of $13.6-16.4 \times 4.6-$ $5.2 \mu \mathrm{m}$, mathching well with previous descriptions of the fungi (Gunnell and Gubler, 1992). There were no clear morphological differences among C. panacicola, $C$. higginsianum, $C$. coccodes and $C$. destructivum. The conidia of four species in common are elongated fusiform, usually pointed to one end and also in their size overlapped each other except $C$. coccodes in conidial width is somewhat wider than the other three species (Fig. 1; Table 2). The results of conidial morphology agreed well with previous descriptions for the respective species (Nakata and Takimoto, 1922; Sutton, 1980; 1992).

Morphology of conidial appressoria was compared among the Colletotrichum species. The appressorial shape of $C$. panacicola showed minor differences to that of $C$. gloeosporioides and their size overlapped to a significant degree. C. panacicola isolates were usually irregularly lobed, sometimes clavate and measured 6.0-11.3 $\times 4.4$ $7.9 \mu \mathrm{m}$, with a mean range of 7.8-8.6 $\times 5.5-6.3 \mu \mathrm{m}$. $C$. gloeosporioides isolates were clavate, ovate or irregularly lobed, and measured $6.5-10.1 \times 5.3-7.8 \mu \mathrm{m}$, with a mean range of $8.1-8.5 \times 6.0-6.9 \mu \mathrm{m}$. There were no clear differences in appressorial morphology among C. panacicola, C. higginsianum, C. coccodes and C. destructivum (Fig. 1; Table 2).

Colletotrichum colonies on PDA were compared. There were clear differences in colony morphology between $C$. panacicola and C. gloeosporioides (Fig. 1). C. panacicola isolates were 67 to $70 \mathrm{~mm}$ after 7 days, consisting of sparse aerial mycelium, grayish yellow brown to dark olive green in the central region and yellowish white towards the margin, whereas $C$. gloeosporioides were 83 to $85 \mathrm{~mm}$ after 7 days, consisting of floccose aerial mycelium and grayish yellow green on the surface. Colonies of C. higginsianum, C. destructivum and C. coccodes showed also distinct differences. C. higginsianum isolates C97027 and C08122 were 68 to $73 \mathrm{~mm}$ after 7 days, dark yellowish brown or yellowish gray on center of surface and dark yellowish brown or dull orange in reverse side. C. destructivum isolate C08077 was 62 to $63 \mathrm{~mm}$, olive color in the central region and pale orange towards the margin on top side, yellowish brown on reverse side. $C$. coccodes isolates C07046 and C96002 were 42 to $49 \mathrm{~mm}$ and grew slowly, olive or dark olive gray on top and reverse side.

Analysis of rDNA-ITS and combined genes (actin + EF1- $\alpha$ + GS) sequences. Size polymorphism and sequence similarity derived from the sequences of rDNA-ITS region and combined multi-locus genes were investigated. The length of the rDNA-ITS from Colletotrichum species ranged from $487 \mathrm{bp}$ to $500 \mathrm{bp}$ and yield 507 aligned nucleotide positions for all species included in the alignment. The nucleotide size for alignment was $499 \mathrm{bp}$ in both C. panacicola and C. higginsianum, 487 bp in C. gloeosporioides and $500 \mathrm{bp}$ in $C$. destructivum. Comparative analysis of the rDNA region containing the two internal transcribed spacers (ITS1 and ITS2) and 5.8S rRNA gene revealed that nucleotide sequences of the $5.8 \mathrm{~S}$ in all tested taxa were highly conserved but those of their ITS regions 
Kyung Jin Choi et al.

Table 2. Morphology of Colletotrichum panacicola and other Colletotrichum species

\begin{tabular}{|c|c|c|c|c|c|c|c|c|c|}
\hline \multirow{3}{*}{ Species } & \multirow{3}{*}{ Isolate } & \multicolumn{3}{|c|}{ Colony } & \multicolumn{2}{|l|}{ Conidium } & \multicolumn{3}{|c|}{ Appressorium } \\
\hline & & \multirow{2}{*}{$\begin{array}{l}\text { Diameter }^{\mathrm{a}} \\
\text { (mm) }\end{array}$} & \multicolumn{2}{|c|}{ Color $^{\mathrm{b}}$} & \multicolumn{2}{|l|}{ Size $(\mu \mathrm{m})$} & \multirow{2}{*}{ Shape $^{d}$} & \multicolumn{2}{|l|}{ Size $(\mu \mathrm{m})$} \\
\hline & & & Top & Reverse & Range & Mean & & Range & Mean \\
\hline \multirow[t]{3}{*}{ C. panacicola } & 48 & 69 & DOG(138) & DOG(138) & B $14.3-19.9 \times 4.0-4.7$ & $17.0 \times 4.4$ & CL & $6.0-8.9 \times 4.8-7.9$ & $7.9 \times 6.3$ \\
\hline & $\mathrm{C} 08061$ & 68 & DOG(138) & DOG(138) & F, TAB $11.2-19.1 \times 3.3-4.7$ & $16.4 \times 4.0$ & IRL, CL & $6.5-9.6 \times 4.4-6.5$ & $7.8 \times 5.6$ \\
\hline & C08087 & 68 & DOG(138) & DOG(138) & F, TAB $15.1-20.5 \times 3.8-4.8$ & $18.3 \times 4.3$ & IRL, CL & $6.3-11.3 \times 4.9-6.4$ & $8.6 \times 5.5$ \\
\hline \multirow[t]{2}{*}{ C. higginsiamum } & C97027 & 68 & $\begin{array}{c}\mathrm{YG}(68) \\
\mathrm{DYB}(76)\end{array}$ & DYB(76) & F, TAB $15.7-22.7 \times 3.9-4.9$ & $19.0 \times 4.4$ & $\mathrm{IR}, \mathrm{OV}$ & $6.2-9.2 \times 4.9-6.9$ & $7.8 \times 6.0$ \\
\hline & $\mathrm{C} 08122$ & 70 & YG(68) & $\begin{array}{l}\text { YC } \\
\text { DC }\end{array}$ & AB $15.3-22.2 \times 3.7-5.0$ & $19.1 \times 4.4$ & , IR & $5.8-10.1 \times 4.8-7.0$ & $7.4 \times 5.5$ \\
\hline C. dest & C08077 & 62 & $\begin{array}{l}\mathrm{O}(105) \\
\mathrm{PO}(60)\end{array}$ & $\begin{array}{c}\mathrm{O}(105) \\
\mathrm{YW}(92)\end{array}$ & $313.8-19.4 \times 3$ & 16.8 & & $7.8-1$ & $9.6 \times 7.4$ \\
\hline \multirow[t]{2}{*}{ C. coccodes } & $\mathrm{C} 07046$ & 45 & $\mathrm{O}(105)$ & $\mathrm{O}(105)$ & F, TAB $13.2-23.0 \times 4.0-5.7$ & $18.4 \times 4.7$ & IR, CL & $7.0-12.2 \times 4.5-7.4$ & $8.7 \times 5.9$ \\
\hline & C96002 & 49 & DOG(138) & DOG(138) & F, TAB $12.7-17.4 \times 4.0-5.6$ & $15.3 \times 4.6$ & $\mathrm{IR}, \mathrm{CL}$ & $6.3-10.8 \times 4.2-6.4$ & $8.2 \times 5.6$ \\
\hline \multirow{2}{*}{$\begin{array}{l}\text { C. gloeosporio- } \\
\text { ides }\end{array}$} & $\mathrm{C} 07008$ & 85 & $\mathrm{O}(105)$ & DOG(138) & C, ROB $11.2-16.9 \times 3.8-5.5$ & $13.6 \times 4.6$ & $\mathrm{CL}, \mathrm{OV}$ & $6.5-10.1 \times 5.3-6.6$ & $8.5 \times 6.0$ \\
\hline & C07009 & 83 & DG (144) & DOG (138) & C, TAO $10.0-22.9 \times 4.4-6.5$ & $16.4 \times 5.2$ & OV, IR & $7.3-9.1 \times 6.1-7.8$ & $8.1 \times 6.9$ \\
\hline
\end{tabular}

${ }^{a}$ Colony diameter was measured 7days after inoculation

${ }^{\mathrm{b}}$ A serial number of Munsell renovation color system today's color/300, DG: dull green, DO: dull orange, DOG: dark olive green, DYB: dark yellowish brown, GYB: yellowish brown, PO: pale orange, O: olive, YB: yellowish brown, YG: yellowish gray, YW: yellowish white

${ }^{\mathrm{C}} \mathrm{C}$ : cylindrical; F: fusiform; TAB: tapered to both ends; TAO: tapered to one end; ROB: rounded both ends

${ }^{\mathrm{d}} \mathrm{CL}$ : clavate, IR: irregular, IRL: irregular lobed, OV: ovate.

were variable. In particular, nucleotide variations of the ITS1 $(6.7 \%)$ were two times higher than those of ITS2 $(3.2 \%)$. The difference of nucleotide variations between ITS1 and ITS2 was consistent with results of previous research (Cano et al., 2004; Sreenivasaprasad et al., 1996).
The ITS sequences from $C$. panacicola isolates shared homology of 87.3-87.5\% with C. gloeosporioides isolates, 92.9 to $93.1 \%$ with $C$. coccodes isolates However, the sequences showed high level of homology of 99.0-99.5\% with $C$. higginsianum and C. destructivum.

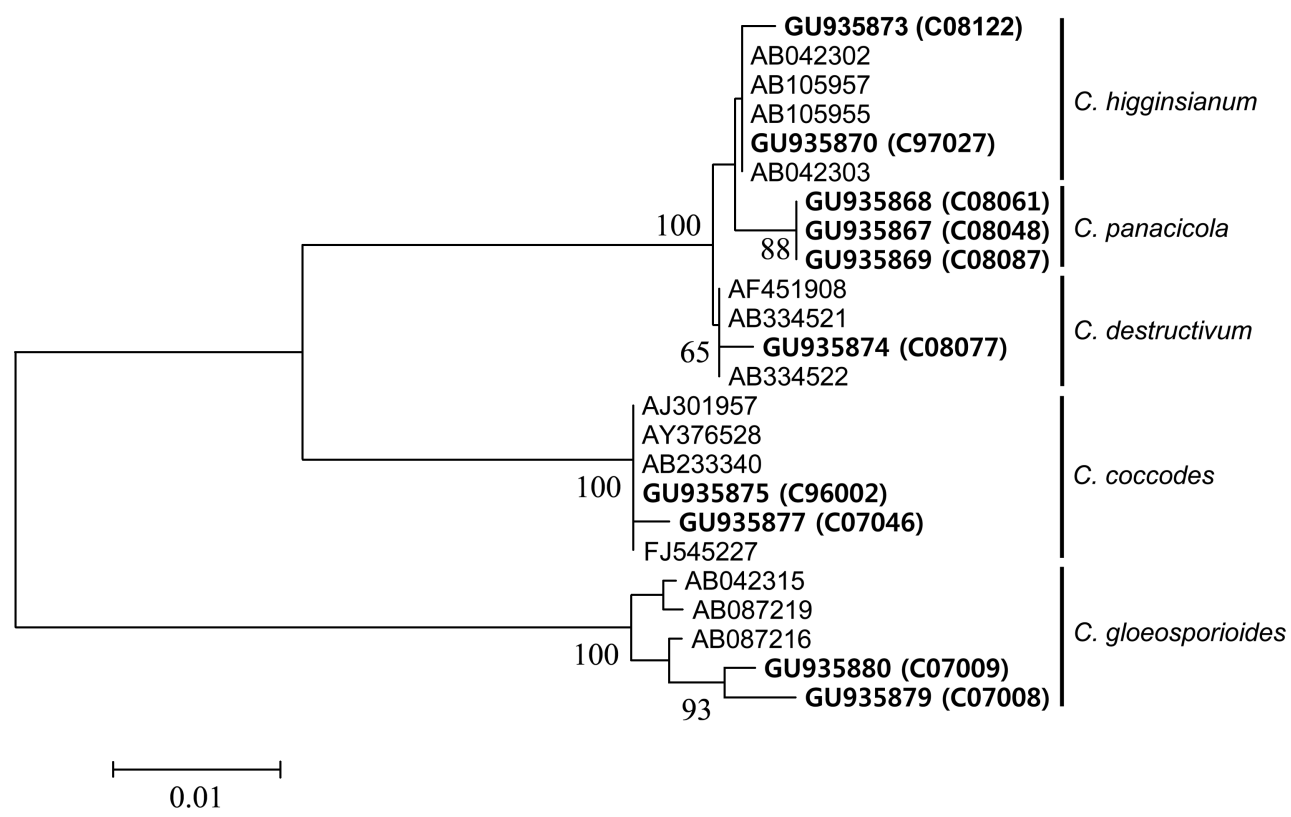

Fig. 2. A neighbor-joining tree derived from sequences of rDNA-ITS region of Colletotrichum spp. Numbers on nodes $(>60 \%)$ represent bootstrap values (\%) from 1000 replicates. A phylogenetic tree was conducted using MEGA 4.0 with kimura-two parameter model. The letters in parentheses refer to isolate numbers. Bar represents 0.01 substitutions per site. 


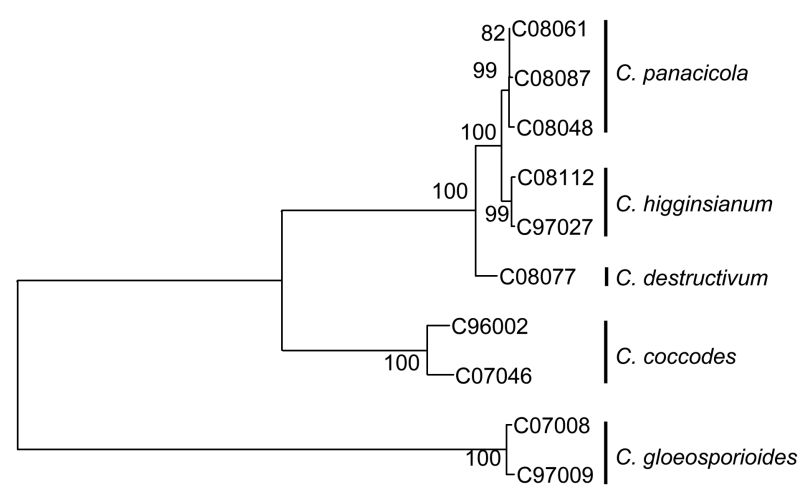

0.05

Fig. 3. A neighbor-joining tree derived from sequences of combined multi-locus gene (actin $+\mathrm{EF} 1-\alpha+\mathrm{GS})$ of Colletotrichum spp. Numbers on nodes $(>60 \%)$ represent bootstrap values (\%) from 1000 replicates. A phylogenetic tree was conducted using MEGA 4.0 with kimura-two parameter model. Bar represents 0.05 substitutions per site.

Analysis of the combined data set of multi-locus sequences (actin + EF1- $\alpha+\mathrm{GS}$ ) revealed that the length of Colletotrichum species ranged from 2318 to $2377 \mathrm{bp}$, with alignment of $2553 \mathrm{bp}$. The size of the nucleotide sequence for alignment was $2349 \mathrm{bp}$ in C. panacicola isolates, 2358 to 2365 bp in C. higginsianum, 2332 to 2341 bp in C. gloeosporioides and 2377 bp in C. destructivum. In the sequences of combined multi-locus gene, $C$. panacicola isolates showed similarity of $62.4-62.6 \%$ with
C. gloeosporioides, $71.2-71.5 \%$ with C. coccodes, 97.8 $98.1 \%$ with $C$. higginsianum and $95.2-95.3 \%$ with $C$. destructivum.

Phylogenetic relationships. Phylogenetic analysis based on the sequences of rDNA-ITS showed that $C$. panacicola is clearly differentiated from $C$. gloeosporioides and $C$. coccodes with a high bootstrap support of $100 \%$ but from $C$. higginsianum and C. destructivum with bootstrap support less than $60 \%$ (Fig. 2).

Sequences analysis of combined multi-locus genes provided higher resolution among the five Colletotrichum species than ITS (Fig. 3). C. panacicola was distinctly separated from the other Colletotrichum species with bootstrap support of $100 \%$ and was positioned far from $C$. gloeosporioides and C. coccodes. The Colletotrichum species which were not significantly differentiated in an ITSbased phylogenetic tree, C. panacicola, C. higginsianum and $C$. destructivum were also further separated each other with bootstrap support of $100 \%$. Taken together, a phylogenetic tree derived from the sequences of combined multi-locus genes led to much higher resolution for the delimitation of $C$. panacicola from other species than ITS.

Pathogenicity. Pathogenicity of the five Colletotrichum species was tested on their host and on other plants (Table 3). C. panacicola isolates on the leaves of Korean ginseng induced circular dark brown lesions 4 days after inoculation. The lesions developed and no major differences in pathogenicity were observed among the isolates. Disease

Table 3. Pathogenicity of Colletotrichum spp. to leaves of several crops by artificial inoculation

\begin{tabular}{|c|c|c|c|c|c|c|c|c|c|}
\hline \multirow{3}{*}{ Species } & \multirow{3}{*}{ Isolate } & \multicolumn{8}{|c|}{ Disease severity $^{\mathrm{a}}$} \\
\hline & & \multicolumn{2}{|c|}{ Ginseng } & \multicolumn{2}{|c|}{ Radish } & \multicolumn{2}{|c|}{ Tomato } & \multicolumn{2}{|c|}{ Soy bean } \\
\hline & & $\mathrm{W}^{\mathrm{b}}$ & $\mathrm{UW}^{\mathrm{c}}$ & $\mathrm{W}$ & UW & $\mathrm{W}$ & UW & $\mathrm{W}$ & UW \\
\hline \multirow[t]{3}{*}{ C.panacicola } & $\mathrm{C} 08048$ & + & + & - & - & - & - & - & - \\
\hline & $\mathrm{C} 08061$ & + & + & - & - & - & - & - & - \\
\hline & $\mathrm{C} 08087$ & ++ & + & - & - & - & - & - & - \\
\hline \multirow[t]{2}{*}{ C. higginsianum } & C97027 & + & - & ++ & $H$ & + & - & - & - \\
\hline & $\mathrm{C} 08122$ & - & - & + & + & - & - & + & - \\
\hline C. destructivum & $\mathrm{C} 08077$ & - & - & - & - & + & - & +++ & - \\
\hline \multirow[t]{2}{*}{ C. coccodes } & $\mathrm{C} 96002$ & + & - & - & - & + & - & + & - \\
\hline & $\mathrm{C} 07046$ & - & - & + & + & +++ & ++ & + & - \\
\hline \multirow[t]{2}{*}{ C. gloeosporioides } & $\mathrm{C} 07008$ & - & - & - & - & - & - & + & - \\
\hline & $\mathrm{C} 07009$ & - & - & - & - & - & - & - & - \\
\hline Control & & - & - & - & - & - & - & - & - \\
\hline
\end{tabular}

${ }^{\mathrm{a}}$ Disease severity on ginseng, radish and tomato was determined on the basis of lesion diameter measured 5 days after inoculation and observed 10 days after inoculation on soybean, respectively.,$-<3.5 \mathrm{~mm}$ lesion;,$+ 3.5-7.0 \mathrm{~mm}$ lesion;,$++ 7.0-10.5 \mathrm{~mm}$ lesion; +++, $>10.5 \mathrm{~mm}$ lesion ${ }^{\mathrm{b}}$ wounded

${ }^{\mathrm{c}}$ unwounded 
severity on leaves with the wound treatment was slightly higher or similar to that of the unwounded leaves. No symptoms developed on the leaves of other hosts including radish, tomato and soybean.

The lesions on leaves of Korean ginseng inoculated with C. gloeosporioides isolates $\mathrm{C} 07008$ and $\mathrm{C} 07009 \mathrm{did}$ not appear. C. higginsianum $\mathrm{C} 97027$ and C. coccodes C96002 showed weak responses on wounded leaves of Korean ginseng, while C. higginsianum, C. coccodes and C. destructivum produced lesions on leaves of their host plants.

\section{Discussion}

C. panacicola was first described by Takimoto (1919). Later, Nakata and Takimoto (1922) provided a detailed description for the causal fungus of leaf blight of Korean ginseng. However, the species in Korea has been regarded as a synonym of C. gloeosporioides, a species complex encompassing diverse groups of strains and biotypes ( $\mathrm{Yu}$, 1992; Yu and Ohh, 1993). In addition, Mcpartland and Hosoya (1998) found that morphology of $C$. panacicola is similar to that of $C$. coccodes (Wallr.) Hughes.

C. panacicola could be distinguished from C. gloeosporioides using conidial morphology but not from $C$. higginsianum, C. destructivum and C. coccodes. C. panacicola could also be distinguished from $C$. gloeosporioides using colony features. The former grew slower than the latter, and both species showed different colony colors. Colony radial growth of $C$. panacicola, $C$. higginsianum and $C$. destructivum was not informative for their speciation, but colony colors revealed difference among them. In short, although conventional methods can be used for identification of the five Colletotrichum species, they provided limited information to delimitate C. panacicola from other morphologicaly similar Colletotrichum species (Talhinhas et al., 2005; Whitelaw-Weckert et al., 2007).

To overcome limitations of morphological approaches for determination of Colletotrichum species, molecular techniques have been employed (Guerber et al., 2003; Johnston and Jones, 1997; Lubbe et al., 2004; Talhinhas et al., 2002). Although ITS regions have known to be potentially informative regions for phylogenetic studies at species level, they were not informative enough to resolve relationships among the $C$. panacicola and its morphologically similar species. Moriwaki et al. (2002) revealed that $C$. destructivum was not separated from $C$. higginsianum, C. linicola and C. fuscum based on the sequences of ITS1 region. In addition, Sreenivasaprasad et al. (1996) reported that $C$. destructivum and $C$. linicola were not differentiated based on ITS1 sequences.

The sequence data from the three independent loci (actin + EF1- $\alpha+\mathrm{GS}$ ) were combined and used to complement the rDNA-ITS sequencing. A phylogenetic analysis derived from combined multi-locus sequences revealed that $C$. panacicola is not only differentiated from $C$. gloeosporioides and C. coccodes but also sufficiently differentiated from $C$. higginsianum and $C$. destructivum with $100 \%$ bootstrap support. Analysis using the combined dataset has been used for recognition of fungal species, including Fusarium spp. (O'Donnell et al., 1998). In this study, the phylogenetic tree based on sequences of the combined genes provided much better resolution for delimitation of $C$. panacicola from other Colletotrichum species than the rDNA-ITS regions.

Artificial inoculation of Colletotrichum species revealed that $C$. panacicola is pathogenic on leaves of Korean ginseng but $C$. gloeosporioides is not. Accordingly, $C$. panacicola was confirmed as a major pathogen causing anthracnose on Korean ginseng. Colletotrichum isolates from radish, tomato and soybean induced severe symptoms on their host plants by artificial inoculation but weak or no symptoms on other host plants. C. panacicola and other Colletotrichum species used in this study showed host specificity. Taxonomy of Colletotrichum species based on the host specificity has been accepted as a criterion to characterize species by previous workers (Farr et al., 2006; Lubbe et al., 2004; Nirenberg et al., 2002; Sutton, 1980). Although C. coccodes was isolated from soil planted with American ginseng (Panax quinquefolius L.) in Wisconsin, pathogenicity of the fungus on ginseng was not described (Mcpartland, 1985). C. coccodes isolate C96002 produced lesions on wounded leaves of Korean ginseng. However, whether the fungus in fields actually causes ginseng anthracnose or not is unclear and requires further investigation.

In conclusion, this work clearly demonstrates that $C$. panacicola is an independent taxon distinguishable from C. gloeosporioides and other morphologically similar Colletotrichum species based on their morphological, cultural and molecular characteristics and pathogenicity.

\section{References}

Cano, J., Guarro, J. and Gene, J. 2004. Molecular and morphological identification of Colletotrichum species of clinical interest. J. Clin. Microbiol. 42:2450-2454.

Carbone, I. and Kohn, L. M. 1999. A method for designing primer sets for speciation studies in filamentous ascomycetes. Mycologia 91:553-556.

Chung, H. S. and Bae, H. W. 1979. Ginseng anthracnose in Korea: Factors affecting primary inoculum, growth of the pathogen, disease development and control. Korean J. Plant Protect. 18:35-41. 
Farr, D. F., Aime, M. C., Rossman, A. Y. and Palm, M. E. 2006. Species of Colletotrichum on Agavaceae. Mycol. Res. 110: 1395-1408.

Felsenstein, J. 1985. Confidence limits on phylogenies: An approach using the bootstrap. Evolution 39:783-791.

Guerber, J. C. Correll, J. C. and Johnston, P. R. 2003. Characterization of diversity in Colletotrichum acutatum sensu lato by sequence analysis of two gene introns, mtDNA and intron RFLPs, and mating compatibility. Mycologia 95:872-895.

Gunnell, P. S. and Gubler, W. D. 1992. Taxonomy and morphology of Colletotrichum species pathogenic on strawberry. Mycologia 84:157-165.

Johnston, P. R. and Jones, D. 1997. Relationships among Colletotrichum isolates from fruit-rots assessed using rDNA sequences. Mycologia 89:420-430.

Kimura, M. 1980. A simple method for estimating evolutionary rates of base substitutions through comparative studies of nucleotide sequences. J. Mol. Evol. 16:111-120.

Lubbe, C. M., Denman, S., Cannon, P. F., Groenewald, J. Z., Lamprecht, S. C. and Crous, P. W. 2004. Characterization of Colletotrichum species associated with disease of Proteaceae. Mycologia 96:1268-1279.

Mcpartland, J. M. 1985. Organisms isolated from soil previously planted in American ginseng. Hamburg, WI: Fromm Brothers, Inc: Technical Report, Supplement. 5pp.

Mcpartland, J. and Hosoya, T. 1998. Species of Colletotrichum on ginseng (panax). Mycotaxon 67:3-8.

Moriwaki, J., Tsukiboshi, T. and Sato, T. 2002. Grouping of Colletotrichum species in Japan based on rDNA sequences. $J$. Gen. Plant Pathol. 68:307-320.

Nakada, K. and Takimoto, S. 1922. Studies on ginseng diseases in Korea. Bull. Agri. Exp. Stat. Chosen 5:1-81 (in Japanese).

Nirenberg, H. I., Feiler, U. and Hagedorn, G 2002. Description of Colletotrichum lupini comb. nov. in modern terms. Mycologia 94:307-320.

O’Donnell, K. E., Cigelnik, H. I. and Nirenberg 1998. Molecular systematics and phylogeography of the Gibberella fujikuroi species complex. Mycologia 90:465-493.

Rehner, S. A. 2001. Primers for elongation factor 1- $\alpha$ (EF1-a). http://www.nacse.org/yfaaberg/aftol/EF1primer.pdf.

Saitou, N. and Nei, M. 1987. The neighbor-joining method: a new method for reconstructing phylogenetic trees. Mol. Biol. Evol. 4:406-425.

Sreenivasaprasad, S., Mills, P. R., Meehan, B. M. and Brown, A. E. 1996. Phylogeny and systematics of 18 Colletotrichum spe- cies based on ribosomal DNA spacer sequences. Genome 39:499-512.

Stewart, C. N. and Via, L. E. 1993. A rapid CTAB DNA isolation technique useful for RAPD fingerprinting and other PCR applications. Biotechniques 14:748-749.

Sutton, B. C. 1980. The Coelomycetes: Fungi Imperfecti with Pycnidia, Acervuli and Stromata. Commonwealth Mycological Institute, Kew, Surrey, England.

Sutton, B. C. 1992. The genus Glomerella and its anamorph Colletotrichum. In: Colletotrichum: Bailey, J. A. and Jeger, M. J. eds. Biology, Pathology and Control. CAB International, Wallingford, Oxon, UK.

Takimoto, S. 1919. Colletotrichum panacicola Uyeda and Takimoto. Chosen Nokwai ho 14:24-25 (In Japanase).

Talhinhas, P. S., Sreenivasaprasad, J. Neves-Martins and H. Oliveira. 2002. Genetic and morphological characterization of Colletotrichum acutatum causing anthracnose of lupins. Phytopathology 92:986-996.

Talhinhas, P. S., Sreenivasaprasad, J., Neves-Martins, H. and Oliveira 2005. Molecular and phenotypic analyses reveal association of diverse Colletotrichum acutatum groups and a low level of C. gloeosporioides with anthracnose. Appl. Environ. Microbiol. 71:2987-2998.

Tamura, K., Dudley, J., Nei, M. and Kumar, S. 2007. MEGA4: Molecular Evolutionary Genetics Analysis (MEGA) software version 4.0. Mol. Biol. Evol. 24:1596-1599.

Thompson, J. D., Gibson, T. J., Plewniak, F., Jeanmougin, F. and Higgins, D. G 1997. The CLUSTAL_X windows interface: flexible strategies for multiple sequence alignment aided by quality analysis tools. Nucleic Acids Res. 25:4876-82.

Whitelaw-Weckert, M. A., Curtin, S. J., Huang, R., Steel, C. C., Blanchard, C. and Roffey, P. E. 2007. Phylogenetic relationships and pathogenicity of Colletotrichum acutatum isolates from grape in subtropical Australia. Plant Pathol. 56:448463.

White, T. J., Bruns, T., Lee, S. and Taylor, J. 1990. Amplification and direct sequencing of fungal ribosomal RNA genes for phylogenetics. In: Innis, M. A., Gelfand, D. H., Sninsky, J. J. and White, T. J. eds. PCR protocols, a guide to methods and applications. New York, USA: Academic Press, 315-322.

Yu, Y. H. 1992. The status of past and present research on ginseng diseases in Korea. Korean J. Ginseng Sci. 16:162-163 (in Korean).

Yu, Y. H. and Ohh, S. H. 1993. Research on ginseng diseases in Korea. Korean J. Ginseng Sci. 17:61-68 (in Korean). 